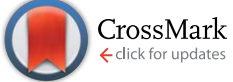

Cite this: RSC Adv., 2016, 6, 16234

Received 30th November 2015 Accepted 30th January 2016

DOI: $10.1039 / \mathrm{c} 5 \mathrm{ra} 25388 \mathrm{~h}$

\section{Improved adsorption properties of granulated copper hexacyanoferrate with multi-scale porous networks $\uparrow$}

\author{
Kyoung-Moo Lee, ${ }^{a}$ Tohru Kawamoto, ${ }^{a}$ Kimitaka Minami, ${ }^{a}$ Akira Takahashi, ${ }^{a}$ \\ Durga Parajuli, ${ }^{a}$ Gentoku Kido, ${ }^{\mathrm{b}}$ Kazunori Yoshino ${ }^{\mathrm{b}}$ and Hisashi Tanaka*a
}

www.rsc.org/advances

Designed porous copper hexacyanoferrate micro-capsule beads (CuHCF-MCB) were prepared using freeze-drying (FD). Multi-scale porous networks composed of Angstrom, nanometer, and micrometer sizes were obtained in the desired shapes using a simple drying process. They provide special benefits such as fast kinetics and high capacity. The Cs adsorption equilibrium and kinetics fit the pseudosecond-order kinetic model well. The adsorption rate of FD-CuHCFMCB was improved to about 15 times higher than that of the heatdrying process because of the highly multi-scale porous structure of FD-CuHCF-MCB, which facilitated solution flow and rapid iondiffusion inside the MCB.

Porous coordinated polymers (PCPs) such as metal-organic frameworks (MOFs) and Prussian blue analogues (PBAs) have attracted attention during the past two decades because of their potential applications for storage, ${ }^{\mathbf{1 , 2}}$ separation, ${ }^{3,4}$ recovery, ${ }^{5,6}$ and catalysis $^{7-9}$ in gas and liquid phases. Among the various PCP applications, they have been studied mainly as an adsorbent because of their particular properties. ${ }^{\mathbf{1 0 - 1 3}}$ Success in adsorbents is related to the following specific attributes of these materials: (1) high surface area and large pore volume; (2) rapid sorption; (3) good selectivity; (4) environmental safety; and (5) high stability. This functionality of PCPs results from their high porosity, as shown in crystal structure of Fig. 1. In fact, PCPs have often been used in fine powder form (e.g. nanoparticles). ${ }^{\mathbf{1 4 - 1 8}}$ However, materials of fine powders present shortcomings such as difficulty of handling and safety hazards resulting from inhaling nanoparticles. For easier and safer practical use of PCP fine powders, a form improvement such as granulation is absolutely necessary. Therefore, many

${ }^{a}$ Nanomaterials Research Institute (NMRI), National Institute of Advanced Industrial Science and Technology (AIST), 1-1-1 Higashi, Tsukuba, Ibaraki 305-8565, Japan. E-mail: hisashi.tanaka@aist.go.jp; Fax: +81 29861 6288; Tel: +81 298614603 ${ }^{b}$ Central Research Laboratory, Technology \& Development Division, Kanto Chemical Incorporated Company, 7-1, Inari 1-chome, Soka, Saitama 340-0003, Japan

$\uparrow$ Electronic supplementary information (ESI) available. See DOI: $10.1039 / \mathrm{c} 5 \mathrm{ra} 25388 \mathrm{~h}$ researchers have reported various materials immobilizing nanoparticles on filter matrixes with binders such as organic and inorganic polymers. ${ }^{19-24}$ In such cases, because the binder often obstructs the liquid-gas flow path and covers the adsorbent surface, the adsorption rate tends to be lower because of lower accessibility or contact probability between the adsorbent and adsorbed substance (gas or liquid, etc.). Therefore, for improvement of the sorption rate, tuning of the porous structure including the matrix is important to raise permeability. ${ }^{25-28}$

The IUPAC defines porosity size as presented in Fig. 1 and as follows: microporous means smaller than $2 \mathrm{~nm}$ diameter, mesoporous is $2-50 \mathrm{~nm}$ diameter, and macroporous is larger than $50 \mathrm{~nm} .^{29}$ The micropore size determines the PCP basic functions. The mesopores and macropores formed by the agglomerated secondary particles and the matrix binder supporting PCPs are important for the liquid-gas flow path. For adsorbent use in water, the minimum necessary pore size is larger than sub-micrometer size at atmospheric pressure..$^{30-32}$

An organic polymer, metal alginate, has been used frequently as a supporting material on a matrix or as a matrix itself. ${ }^{33,34}$ Alginate and divalent or multivalent cations form ionotropic gels such as $\mathrm{Ca}^{2+} /$ alginate. One such fabrication, heat-air dried micro-capsule beads (MCBs) was reported ${ }^{35}$ and the MCB of metal hexacyanoferrate (MHCF) became commercially available from Kanto Chemical Co. Inc.

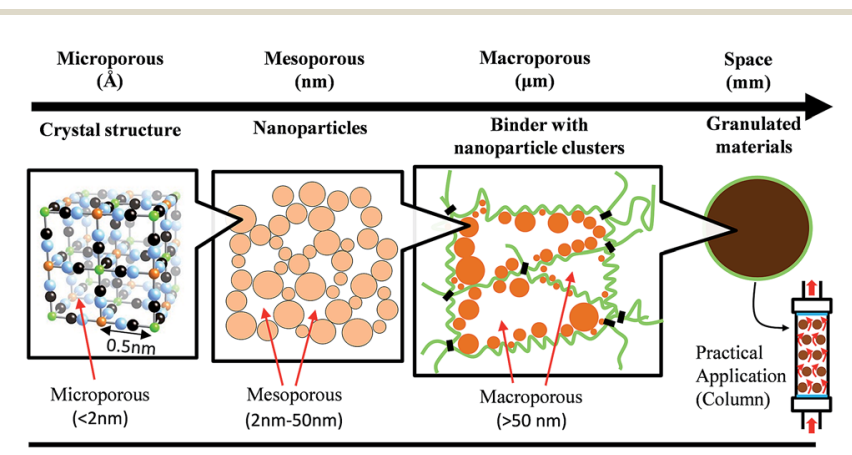

Fig. 1 Schematic presentation of porous designed micro-capsule beads for practical application. 
After the Fukushima Daiichi Nuclear Plant accident in 2011, practical decontamination studies of radionuclides were conducted for various targets such as contaminated water, soil, plants, ash, and sewage sludge. ${ }^{36-39}$ Radioactive cesium is an especially harmful nuclear fission product because of its long half-life and large amounts released to the environment. Therefore, a good adsorbent material with high Cs selectivity has been requested, even from water, such as seawater, containing high alkali metal contents. One potential Cs adsorbent is copper hexacyanoferrate (CuHCF) because of its high Cs selectivity, high capacity, rapid sorption, good thermal and radiation stability, low cost, low toxicity, and chemical stability in a wide $\mathrm{pH}$ range. ${ }^{\mathbf{4 0 - 4 3}}$ Additionally, the basic adsorption performance of the CuHCF was improved by nanoparticulation and surface modification method, as we reported previously. ${ }^{\mathbf{4 4 , 4 5}}$ For the practical use of nanoparticle of CuHCF, such as a column packing adsorbent (Fig. 1), it is necessary to make it granulate. However, the granulation is often lowered the adsorption rate because of the slow diffusion rate of inner beads.

In this paper, our strategy for the improvement of adsorption rate is to tune the permeability of adsorbent by simple processes, that is, granulated by MCB method and dried using different processes of heat-drying (HD) and freeze-drying (FD). FD method has advantage to keep the original porous structures without degradation. We discussed the effects on the adsorption rate by desired multi-scale porous networks used to maintain the liquid-gas flow path.

Insoluble $\mathrm{CuHCF}\left(\mathrm{K}_{2} \mathrm{Cu}_{3}\left[\mathrm{Fe}(\mathrm{CN})_{6}\right]_{2}\right)$ slurry 1 was synthesized by mixing copper(II) sulfate pentahydrate $\left(\mathrm{CuSO}_{4} \cdot 5 \mathrm{H}_{2} \mathrm{O}\right)$ and potassium hexacyanoferrate(II) trihydrate $\left(\mathrm{K}_{4}\left[\mathrm{Fe}(\mathrm{CN})_{6}\right] \cdot 3 \mathrm{H}_{2} \mathrm{O}\right)$. For bead preparation, sodium alginate $\left(\left(\mathrm{NaC}_{6} \mathrm{H}_{7} \mathrm{O}_{6}\right)_{n}\right.$; Kanto Chemical Co. Inc.) and calcium chloride $\left(\mathrm{CaCl}_{2}\right.$; Wako Pure Chemical Industries Ltd.) were used. High-purity water produced using a Milli-Q integral water purification system was used for all experiment processes. The CuHCF dispersion solution (6.0 wt\%) 2 was prepared by re-dispersing the CuHCF powder 3, which was obtained by drying 1 with an evaporator, in Milli-Q water, with stirring by a homogenizer (T.K. Robomix; PRIMIX Corp., Japan) at $16000 \mathrm{rpm}$ for $10 \mathrm{~min}$. The sol solution of CuHCF 4 was prepared by mixing $120 \mathrm{~g}$ of dispersion solution $(6.0 \mathrm{wt} \%) 2$ and $60 \mathrm{~g}$ of sodium alginate solution (3wt\%) (CuHCF : alginate $=8: 2$ ). After the CuHCF sol solution 4 was dropped into the $400 \mathrm{~g}$ of calcium chloride solution ( $2 \mathrm{wt} \%$ ), gelation occurs immediately upon the contact of the alginate and $\mathrm{Ca}^{2+}$, forming homogeneous spherical beads. The resulting beads were washed with $100 \mathrm{~mL}$ of Milli-Q water four times on a vacuum filter to remove residual ions until the conductivity of washing solution dropped below $0.4 \mathrm{mS} \mathrm{cm}^{-1}$.

The wet CuHCF-MCB $\left(\mathrm{K}_{2} \mathrm{Cu}_{3}\left[\mathrm{Fe}(\mathrm{CN})_{6}\right]_{2} \cdot\left(\mathrm{Ca}\left(\mathrm{C}_{6} \mathrm{H}_{7} \mathrm{O}_{6}\right)_{2}\right)_{x}\right) \mathbf{5}$ (Fig. 2(a)) was dried using two methods. One commonly uses heat-drying (HD) process 6 drying in $60{ }^{\circ} \mathrm{C}$ oven for $2 \mathrm{~h}$ (Fig. 2(c)). The other is a freeze-drying (FD) process 7: $20 \mathrm{~g}$ of 5 was quickly frozen by liquid nitrogen and vacuumed using a freeze dryer (FZ-Compact; Labconco Corp., USA) for more than $10 \mathrm{~h}$ (Fig. 2(b)). Hereafter the HD- and FD-CuHCF-MCB are abbreviated as HD- and FD-MCB, respectively.

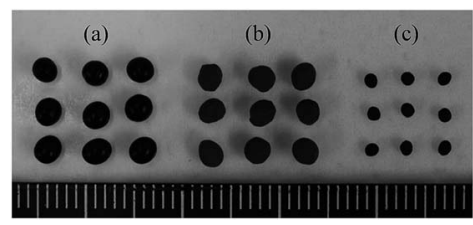

Fig. 2 Photograph of wet-MCB (a) and dried MCBs, both FD- (b) and HD- (c).

Chemical compositions of CuHCF powder 3 and HD-MCB 6 were ascertained using MP-AES (4100 MP-AES; Agilent Technologies Inc., USA) with pre-decomposition using a microwave (MW, Multiwave 3000; PerkinElmer Corp., USA). The crystal structures of the alginate, CuHCF powder and MCBs were evaluated using XRD (D2 phazer; Bruker Analytik, Germany) using $\mathrm{Cu} \mathrm{K} \alpha(\lambda=1.54 \AA)$ radiation in the $2 \theta$ range of $10-70^{\circ}$. The crystal-particle size was evaluated using Scherrer's equation. General vibrational information was evaluated using FT-IR (Nicolet iS5; Thermo Scientific, USA) with pellets made from the mixed sample with $\mathrm{KBr}$.

Cross-sectional images of MCBs were observed with a FESEM (S-4800; Hitachi Ltd., Japan). The SEM images were taken at $5 \mathrm{kV}$ accelerating voltage after Pt coating $(6.5 \mathrm{~nm})$ using an ion sputter coater (E-1030; Hitachi Ltd., Japan). The porosity, pore size, and its distribution on MCBs were measured using mercury intrusion porosimetry (MIP, Autopore IV 9500; Micromeritics, USA) with the diameter range of $0.0065-423 \mu \mathrm{m}$. The pore size was calculated as a function of pressure using and equation of a report ${ }^{46}$ of a study using parameter of $\mathrm{Hg}$ surface tension $\left(0.485 \mathrm{~N} \mathrm{~m}^{-1}\right)$ and contact angle between $\mathrm{Hg}$ and the sample $\left(140^{\circ}\right)$.

For kinetic studies, each $37.5 \mathrm{mg}$ ( $30 \mathrm{mg}$ CuHCF included) of both MCBs was shaken in $30 \mathrm{~mL}$ solutions of different initial $\mathrm{Cs}^{+}$concentration $\left(1 \mathrm{mg} \mathrm{L}^{-1}\right)$ at $25{ }^{\circ} \mathrm{C}$ and $600 \mathrm{rpm}$ frequency with intermittent movement for several setting times, 10, 20, and $30 \mathrm{~min}$, and $1,4,8$, and $24 \mathrm{~h}$. Additionally, a shaking experiment for the equilibrium studies was done to achieve equilibrium for $72 \mathrm{~h}$ in the conditions described above. Each $37.5 \mathrm{mg}$ of both MCBs were shaken in $30 \mathrm{~mL}$ of $200 \mathrm{mg} \mathrm{L}^{-1}$ $\mathrm{CsNO}_{3}$ solution for $72 \mathrm{~h}$. The concentration of residual Cs in the liquid phase was determined using an ICP-MS (NexION300D; PerkinElmer Inc., USA).

Chemical composition analysis revealed that the CuHCF powder 3, HD-MCB 6, and the FD-MCB 7 composition were identical to that of the $\mathrm{HD}$ one, and were determined respectively as $\mathrm{K}_{2.18} \mathrm{Cu}_{2.94}\left[\mathrm{Fe}(\mathrm{CN})_{6}\right]_{2}$ and $\mathrm{K}_{2.28} \mathrm{Cu}_{3.04}\left[\mathrm{Fe}(\mathrm{CN})_{6}\right]_{2}$ $\cdot 0.34 \mathrm{Ca}\left(\mathrm{C}_{6} \mathrm{H}_{7} \mathrm{O}_{6}\right)_{2}$. The $\mathrm{Cu} / \mathrm{Fe}$ and $\mathrm{K} / \mathrm{Fe}$ ratios are 1.47 and 1.09 for CuHCF powder 3, and 1.52, 1.14 for MCB 6, respectively. No significant difference was found between them except for the composition of calcium alginate. Details of results related to the XRD and FT-IR measurements are presented in ESI. $\dagger$ Examinations of FD- and HD-MCB using XRD and FT-IR revealed that few differences existed before and after granulation. Results confirmed that the mixing and granulate process with alginate or drying process of MCB does not affect the CuHCF characteristics or its nanoparticle size. 
The FE-SEM images of the FD- and HD-MCBs are shown in Fig. 3. The macroporous size images differ greatly. Both MCBs have a structure of the small cells made from alginate polymer and the nanoparticle CuHCF supported on the cells. In images of HD-MCB (Fig. 3(b)), however, because the alginate cells are tightly folded and the CuHCF powders are compressed, little vacant space exists. In contrast, results from images in Fig. 3(a) confirmed that macroporous spaces exist in FD-MCB. Here the BET specific surface area $\left(\mathrm{m}^{2} \mathrm{~g}^{-1}\right)$ was measured by gas adsorption measurement (BELSORP-max, MicrotracBEL Corp., Japan) in order to confirm the space area in the MCBs, and it was calculated by $\mathrm{N}_{2}$ adsorption isotherm at $77 \mathrm{~K}$. The value of FD-MCB and CuHCF powder were obtained to $67 \mathrm{~m}^{2} \mathrm{~g}^{-1}$ and $300 \mathrm{~m}^{2} \mathrm{~g}^{-1}$, respectively. On the other hand, the value of HDMCB could not be obtained because of the quite slow equilibrium adsorption. To clarify the porous properties, MIP was used. It is widely used for characterizing pore volumes and sizes in porous solids.

In Fig. 4(a), the cumulative and log differential intrusion volumes by MIP are shown as a function of the pore size diameter. ${ }^{43}$ A large distribution around 1-3 $\mu \mathrm{m}$ for FD-MCB is apparent from the log differential intrusion results, although only a small distribution was observed for HD-MCB. The micrometer-scale porous distribution was also confirmed from the FE-SEM images shown in Fig. 3. The total of cumulative intrusion volume in FD-MCB is almost 27 times larger than that of HD. Additionally, although the cumulative volume of mesopores of about 20-50 $\mathrm{nm}$ in the FD-MCB was higher than that of HD-MCB, the volume of HD-MCB increased rapidly below about $20 \mathrm{~nm}$ (Fig. 4(b)). According to the capillary size and pressure
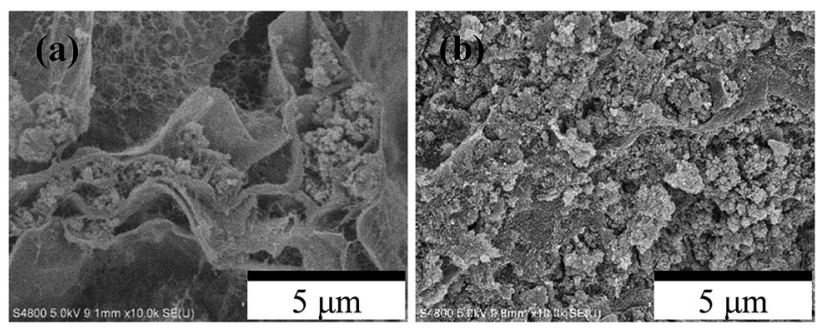

Fig. 3 Cross-sectional FE-SEM images of FD- (a) and HD- (b) MCB.
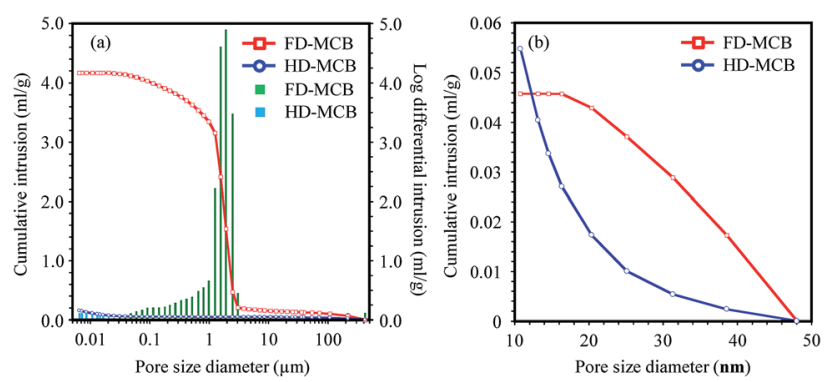

Fig. 4 Porous distribution of FD-MCB and HD-MCB. Cumulative (left $Y$ axis) and log differential (right $Y$ axis) intrusion volumes of whole range data (a) and 10-50 $\mathrm{nm}$ range (set the value to zero the $48 \mathrm{~nm}$ of $X$ axis) (b). relation, the permeable pore size was calculated from the surface tension and contact angle of materials. For the Cs adsorption, water was used as a solvent. The water-permeable minimum pore radius was estimated as $1.437 \mu \mathrm{m}$. The water surface tension in atmospheric pressure is $72.88 \mathrm{mN} \mathrm{m}^{-1}$ (20 $\left.{ }^{\circ} \mathrm{C}\right)$. The wet state can be expressed as $\theta=0$, as described in SI relationship between capillary pressure and pore size. According to the MIP result, the FD-MCB is suited to water treatment. However, mesopores smaller than $50 \mathrm{~nm}$ are permeable materials with low surface tension, such as $\mathrm{CO}_{2}$.

For this study, Cs adsorption experiments were conducted by shaking for $72 \mathrm{~h}$ with various Cs concentrations. The Cs maximum sorption capacity $q_{\max }\left(\mathrm{mg} \mathrm{g}^{-1}\right)$ of the MCBs was calculated using Langmuir model fitting. ${ }^{47}$ The Langmuir model includes the assumptions that adsorption occurs at structurally homogeneous sites and that all sorption sites are energetically identical. The values of $q_{\max }$ are calculated from the slope and are tabulated. The values of $q_{\max }$ of FD-MCB and HD-MCBs respectively exhibit 172.4 and $169.5 \mathrm{mg} \mathrm{g}^{-1}$ (Fig. S2 $\dagger$ ).

For evaluation of the adsorption rate of the HD-MCB and FDMCBs, Cs adsorption experiments were conducted by shaking for $24 \mathrm{~h}$. Although both MCBs adsorb more than $98 \%$ of Cs ions after $24 \mathrm{~h}$, obvious differences were found between the adsorption rate within $1 \mathrm{~h}$, as presented in Fig. 5(a).

Kinetic models provide useful data to elucidate the sorption mechanism. Among the many models, pseudo-second-order models have often been used to calculate adsorbent kinetics. ${ }^{\mathbf{4 8 4 9}}$ A pseudo-second-order kinetic model is presented and discussed for the adsorption rate using shaking test data for $24 \mathrm{~h}$. Actually, $K_{2}$ and $q_{\mathrm{e}}$ can be determined from the $t / q_{t}$ versus the $t$ plot (Fig. 5(b)). The calculated pseudo-second-order model parameters are summarized respectively in Table 1 and ESI. $\dagger$ Application of the kinetic model to the adsorption of MCBs revealed that the values of $K_{2}$ by FD-MCB were improved about 15 times higher than those of HD-MCB. The results of
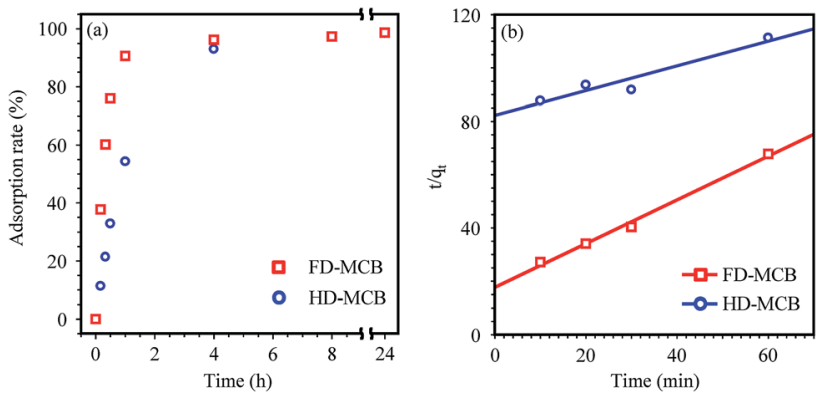

Fig. 5 Adsorption rate (\%) (a) and the pseudo-second-order kinetic model (b) for the $\mathrm{Cs}^{+}$ion sorption onto FD-MCB and HD-MCB.

Table 1 Parameters of pseudo-second-order kinetic models

\begin{tabular}{lll}
\hline & FD-MCB & HD-MCB \\
\hline$K_{2}\left(\mathrm{~g} \mathrm{mg}^{-1} \mathrm{~min}^{-1}\right)$ & 0.0382 & 0.0026 \\
$R^{2}$ & 0.9938 & 0.9206
\end{tabular}


these adsorption tests demonstrated that marked differences exist between the adsorption rates of HD- and FD-MCB. However, the maximum sorption capacity was not so influenced by the pore size distribution caused by dry processes.

Considering the structures and adsorption properties, control of the micrometer-scale porosity is effective for improving Cs adsorption. The highly macroporous (micrometer-scale porous) structure of FD-MCB increases water permeability into the inside of alginate cells and the contact changes between the Cs solution and CuHCF nanoparticles. Consequently, the pore size for water permeation requires approximately several-micrometer size. Considering FD-MCB results, the adsorption rate depends strongly on the pore size because the accessibility or contact probability of solution including Cs ions toward inner MCB is an important parameter. As described above, the mesopores also affect ion diffusion in the secondary particles, as presented in Fig. 1. Considering these results, mesopores are apparently necessary for gas phase applications.

In summary, multi-scale porous CuHCF-MCB with a high adsorption rate was prepared by freeze-drying. Applying pseudo-second kinetic models to the adsorption of Cs to the CuHCF-MCB, the $K_{2}$ of MCB by FD process were improved to about 15 times higher than that of HD process. The rational design and tune porosity of the textural materials by freeze drying are expected to contribute to the practical application of various PCP materials.

\section{Notes and references}

1 C. P. Krap, J. Balmaseda, B. Zamora and E. Reguera, Int. J. Hydrogen Energy, 2010, 35, 10381.

2 I. Spanopoulos, P. Xydias, C. D. Malliakas and P. N. Trikalitis, Inorg. Chem., 2013, 52, 855.

3 J.-R. Li, R. J. Kuppler and H.-C. Zhou, Chem. Soc. Rev., 2009, 38, 1477.

4 H. Mimura, M. Kimura, K. Akiba and Y. Onodera, J. Nucl. Sci. Technol., 1999, 36, 307.

5 F. Cao, C. Zhang, Y. Xiao, H. Huang, W. Zhang, D. Liu, C. Zhong, Q. Yang, Z. Yang and X. Lu, Ind. Eng. Chem. Res., 2012, 51, 11274.

6 N. Janssens, L. H. Wee, S. Bajpe, E. Breynaert, C. E. A. Kirschhock and J. A. Martens, Chem. Sci., 2012, 3, 1847.

7 J. Y. Lee, O. K. Farha, J. Roberts, K. A. Scheidt, S. B. T. Nguyen and J. T. Hupp, Chem. Soc. Rev., 2009, 38, 1450.

8 G. Selvarani, S. K. Prashant, A. K. Sahu, P. Sridhar, S. Pitchumani and A. K. Shukla, J. Power Sources, 2008, 178, 86.

9 M. Ranocchiari and J. A. Bokhoven, Phys. Chem. Chem. Phys., 2011, 13, 6388.

10 B. Hu, B. Fugetsu, H. Yua and Y. Abe, J. Hazard. Mater., 2012, 217, 85.

11 A. K. Vipin, B. Hu and B. Fugetsu, J. Hazard. Mater., 2013, 258, 93.

12 S. Cavenati, C. A. Grande and A. E. Rodrigues, Ind. Eng. Chem. Res., 2008, 47, 6333.
13 J. P. Marco-Lozar, J. Juan-Juan, F. Suarez-Garcia, D. CazorlaAmoros and A. Linares-Solano, Int. J. Hydrogen Energy, 2012, 37, 2370.

14 A. Ranft, S. B. Betzler, F. Haase and B. V. Lotsch, CrystEngComm, 2013, 15, 9296.

15 R. Chen, H. Tanaka, T. Kawamoto, M. Asai, C. Fukushima, M. Kurihara, M. Watanabe, M. Arisaka and T. Nankawa, Electrochem. Commun., 2012, 25, 23.

16 L. He, Y. Liu, J. Liu, Y. Xiong, J. Zheng, Y. Liu and Z. Tang, Angew. Chem., Int. Ed., 2013, 52, 3741.

17 T. A. R. J. Joseyphus, J. Mater. Sci., 2014, 49, 7014.

18 L. D. O'Neill, H. Zhang and D. Bradshaw, J. Mater. Chem., 2010, 20, 5720.

19 G. Chen, Y. Chang, X. Liu, T. Kawamoto, H. Tanaka, A. Kitajima, D. Parajuli, M. Takasaki, K. Yoshino, M. Chen, Y. Lo, Z. Lei and D. Lee, Sep. Purif. Technol., 2015, 143, 146. 20 S. Aguado, J. Canivet and D. Farrusseng, Chem. Commun., 2010, 46, 7999.

21 T. Yasutaka, T. Kawamoto, Y. Kawabe, T. Sato, M. Sato, Y. Suzuki, K. Nakamura and T. Komai, J. Nucl. Sci. Technol., 2013, 50, 674.

22 C. Dwivedi, A. Kumar, J. K. Ajish, K. K. Singh, M. Kumar, P. K. Wattal and P. N. Bajaj, RSC Adv., 2012, 2, 5557.

23 C. Dwivedi, S. K. Pathak, M. Kumar, S. C. Tripathi and P. N. Bajaj, RSC Adv., 2013, 3, 22102.

24 C. Dwivedi, S. K. Pathak, M. Kumar, S. C. Tripathi and P. N. Bajaj, Environ. Sci.: Water Res. Technol., 2015, 1, 153.

25 D. Wu, F. Xu, B. Sun, R. Fu, H. He and K. Matyjaszewski, Chem. Rev., 2012, 112, 3959.

26 F. M. Plieva and B. Mattiasson, Ind. Eng. Chem. Res., 2008, 47, 4131.

27 C. Delchet, A. Tokarev, X. Dumail, G. Toquer, Y. Barre, Y. Guari, C. Guerin, J. Larionova and A. Grandjean, $R S C$ Adv., 2012, 2, 5707.

28 T. Vincent, C. Vincent, Y. Barre, Y. Guari, G. L. Saoutd and E. Guibal, J. Mater. Chem. A, 2014, 2, 10007.

29 J. Rouquerol, D. Avnir, C. W. Fairbridge, D. H. Everett, J. H. Haynes, N. Pernicone, J. D. F. Ramsay, K. S. W. Sing and K. K. Unger, Pure Appl. Chem., 1994, 66, 1739.

30 M. H. A. Alnaief, Ph.D. thesis, Hamburg University of Technology, 2011.

31 M. Tong, L. Li, W. Wang and Y. Jiang, Geophysics, 2006, 71, N33.

32 F. Yang, F. F. Hingerl, X. Xiao, Y. Liu, Z. Wu, S. M. Benson and M. F. Toney, Sci. Rep., 2015, 5, 10635.

33 T. Guo, Y. Hu, X. Gao, X. Ye, H. Liu and Z. Wu, RSC Adv., 2014, 4, 24067.

34 T. Vincent, J.-M. Taulemesse, A. Dauvergne, T. Chanut, F. Testa and E. Guibal, Carbohydr. Polym., 2014, 99, 517.

35 D. Parajuli, A. Takahashi, H. Noguchi, A. Kitajima, H. Tanaka, M. Takasaki, K. Yoshino and T. Kawamoto, Chem. Eng. J., 2016, 283, 1322.

36 A. Kitajima, H. Ogawa, T. Kobayashi, T. Kawasaki, Y. Kawatsu, T. Kawamoto and H. Tanaka, Environ. Sci.: Processes Impacts, 2014, 16, 28.

37 D. Parajuli, A. Takahashi, H. Tanaka, M. Sato, S. Fukuda, R. Kamimura and T. Kawamoto, J. Environ. Radioact., 2015, 140, 78. 
38 I. Tsushima, M. Ogoshi, H. Yamashita and I. Harada, J. Jpn. Soc. Water Environ., 2013, 36, 23.

39 N. Kozai, S. Suzuki, N. Aoyagi, F. Sakamoto and T. Ohnuki, Water Res., 2015, 68, 616.

40 A. Nilchi, R. Saberi, M. Moradi, H. Azizpour and R. Zarghami, Chem. Eng. J., 2011, 172, 572.

41 J. Causse, A. Tokarev, J. Ravaux, M. Moloney, Y. Barre and A. Grandjean, J. Mater. Chem., 2014, 2, 9461.

42 R. Chen, H. Tanaka, T. Kawamoto, M. Asai, C. Fukushima, H. Na, M. Kurihara, M. Watanabe, M. Arisaka and T. Nankawa, Electrochim. Acta, 2013, 87, 119.

43 R. Chen, M. Asai, C. Fukushima, M. Ishizaki, M. Kurihara, M. Arisaka, T. Nankawa, M. Watanabe, T. Kawamoto and H. Tanaka, J. Radioanal. Nucl. Chem., 2015, 303, 1491.
44 A. Takahahshi, N. Minami, H. Tanaka, K. Sue, K. Minami, D. Parajuli, K.-M. Lee, S. Ohkoshi, M. Kurihara and T. Kawamoto, Green Chem., 2015, 17, 4228.

45 K.-M. Lee, A. Takahashi, H. Tanaka, K. H. Kim, M. Kawamura, Y. Abe, M. Ishizaki, M. Kurihara and T. Kawamoto, Bull. Chem. Soc. Jpn., 2015, 88, 1561.

46 E. Vennat, C. Bogicevic, J.-M. Fleureau and M. Degrange, Dent. Mater., 2009, 25, 729.

47 C. Chen, Open Chem. Eng. J., 2013, 7, 24.

48 S. Cataldo, G. Cavallaro, A. Gianguzza, G. Lazzara, A. Pettignano, D. Piazzese and I. Villaescusa, J. Environ. Chem. Eng., 2013, 1, 1252.

49 A. E. Ofomaja, A. Pholosi and E. B. Naidoo, Int. Biodeterior. Biodegrad., 2014, 92, 71. 